Methods STIPU has an advisory group and three working groups for projects dedicated to GP, PFSHS and community STI social marketing. Multidisciplinary groups including academic researchers created work plans to identify needs; develop baseline, process and outcome indicators; develop, promote and disseminate resources and training activities.

Results Identified needs include population health skills, priority population triage, local priority population estimations; resources and training developed include, for GP, STI testing and partner notification tools, practise nurse chlamydia testing card, online and in person STI training modules for doctors and nurses; for PFSHS, priority population calculator and target estimator, state-wide standard operating procedures and triage training. In consultation with academic and corporate health marketers, a social marketing plan includes working with young people's music festivals using online and festival activations. Cross government and non-government youth agencies are now receiving consistent sexual health messaging for local youth work further supporting current school-based sexual health curriculum. External academic evaluation has been undertaken to refine GP project activities.

Conclusion Coordinating three key aspects of the NSW STI Strategy implementation has allowed programme knowledge, practise and outcomes to be considered concurrently. Partner engagement remains strong and early operations and systems research integration has stimulated programme management.

\section{P6.034 POTENTIAL IMPACT OF A PROVINCIAL ELECTRONIC HEALTH RECORDS ON STI/HIV TESTING AT STI CLINICS}

doi:10.1136/sextrans-2013-051184.1188

'G Ogilvie, 'D Taylor, 'M Gilbert, ${ }^{2} \mathrm{M}$ Achen, 'R Lester, BCCDC Provincial STI clinic clericalnursing team. 'University of British Columbia, Vancouver, $B C$, Canada; ${ }^{2} B C$ Centre for Disease Control, Vancouver, BC, Canada

Background Clients who choose to attend sexually transmitted diseases clinics for care express a desire for anonymity and nonjudgmental care. We surveyed a convenience sample of clients attending the $\mathrm{BC}$ Centre for Disease Control (BCCDC) Provincial STI clinic to assess the acceptability of electronic health records (EHR) containing sensitive sexual health information which may be available to healthcare professionals external to the BCCDC STI clinic.

Methods All clients attending the BCCDC STI clinic between July-October 2012 were offered a 16-item questionnaire to determine if it was acceptable for their sexual health information to be made available to their family physician, pharmacist, medical specialist, and nurses at other STI clinics through the provincial EHR. Demographic information was also collected. Frequency analysis was conducted using SPSS-14

Results At total of 378 (227 [60\%] male) individuals completed the survey. Seventy-four percent were 19-39 years old (range 14yrs - > $59 y r s)$. Sixty-seven percent $(n=254)$ were Caucasian and $55 \%$ $(n=209)$ had a university degree. The majority (86\%) of respondents stated they were satisfied with the current computer health record with closed access to external healthcare professionals. One hundred and one $(27 \%)$ respondents stated it would not be acceptable for their family physician $(n=101[27 \%])$, pharmacist $(n=197$ [52\%]), medical specialist ( $\mathrm{n}=106[28 \%]$ ), and nurses in other STI clinics ( $\mathrm{n}=112[30 \%]$ ) to have access their BCCDC STI clinic record. 133 respondents $(30 \%)$ stating they would be less likely to get tested for HIV and STIs and if their BCCDC STI clinic record were made available as part of the provincial EHR.

Conclusion The introduction of a provincial EHR for STI/HIV care information is not acceptable to a significant proportion of clients and may result in reduced screening, posing a threat to the control of sexually transmitted infections in British Columbia. Further monitoring and safeguards should be considered.

\section{P6.035 THE ROAD TO PROJECT OWNERSHIP; THE EXPERIENCE OF SUB GRANTING IN 27 DISTRICTS OF UGANDA}

doi:10.1136/sextrans-2013-051184.1189

J M Matovu, E Tumuhimbise, J Opigo, A Kekitiinwa. Baylor Uganda, Kampala, Uganda

Many donor funded HIV/AIDS programmes have been known to crumble when the donor pulls out. This has largely been attributed to poor sustainability plans by most projects. Since 2008, Baylor Uganda has been implementing an HIV/AIDS programme through sub granting in 27 districts of Uganda. We describe the sub granting experience as a sustainability implementation approach to HIV/ AIDS programmes.

Methods Under Sub granting we provide cash subventions to 27 districts health offices, 267 health facilities and 27 district network of people living with HIV/AIDS (PHA) to implement their own HIV/AIDS priority activities. These funds supplement the meagre government primary health care (PHC) conditional grant. BaylorUganda together with the partners hold annual planning meetings to identify priority areas for HIV/AIDS for funding in line with ministry of health requirements. Funds are released on a quarterly basis to the partners based on their approved work plans and budgets. Baylor staff monitors project implementation on a monthly basis. Supported districts submit technical and financial reports quarterly. Accountability of the district is reviewed and districts are annually categorised according to performance. The size of the grant in subsequent quarters is dependent upon the performance of the partner.

Results Todate all the partners able to identify their priorities, develop work plans and implement their own activities hence fostering ownership and sustainability. Sub granting has helped to create a strong sense of ownership by both the project implementers and the target beneficiaries. Ranking of districts has brought in competition which has improved service delivery as well as accountability. Late implementation and late submission of accountability are still the major challenges.

Conclusion Whereas sub granting faces some challenges, it is a fundamental step towards creating ownership and sustainability of HIV programmes in low resource settings.

\section{P6.036 STIGMA \& DISCRIMINATION AMONG HIV-INFECTED MSM POPULATION IN THE SUB-SAHARAN AFRICA}

doi:10.1136/sextrans-2013-051184.1190

\section{A Mohanty. Kissito Healthcare, Roanoke, VA, United States}

People Living with HIV/AIDS (PLWHA) in Sub-Saharan Africa face stigma and discrimination including significant health challenges. Social, religious and cultural contexts most often contribute to various forms of stigma and discrimination among PLHWA. They pose extra challenges for HIV-infected Men having Sex with Men (MSM) by hindering early interventions among these groups. Although the MSM population affected with HIV are not considered to be a high HIV infection risk group in Sub-Saharan Africa, recent studies have revealed the widespread existence of MSM groups across the region and high rates of HIV infection and HIV risk behaviour among MSM population.

This paper provides a systematic literature review about the stigma and discrimination faced by the MSM population in SubSaharan Africa. The literature review was conducted through the systematic search of several online databases including Pub Med, Medline and Google.com. 